06

\title{
Динамическая прочность титанового сплава с модифицированной электронным пучком поверхностью
}

\author{
(C) Г.Г. Савенков, ${ }^{1,2}$ А.В. Кузнецов, ${ }^{1}$ А.М. Брагов ${ }^{3}$ \\ ${ }^{1}$ Машиностроительный завод „Армалит“, \\ 198097 Санкт-Петербург, Россия \\ ${ }^{2}$ Санкт-Петербургский государственный технологический институт \\ (технический университет), \\ 190013 Санкт-Петербург, Россия \\ ${ }^{3}$ Научно-исследовательский институт механики Национального исследовательского \\ Нижегородского государственного университета им. Н.И. Лобачевского, \\ 603950 Нижний Новгород, Россия \\ e-mail: sav-georgij@yandex.ru
}

(Поступило в Редакцию 13 февраля 2017 г.)

\begin{abstract}
Представлены результаты плосковолновых экспериментов по определению динамической прочности титанового сплава 3М с обработанной электронным пучком микросекундной длительности поверхностью. Показано, что динамическая прочность образцов с обработанной поверхностью выше, чем у образцов без обработки. Металлографический анализ испытанных образцов выявил макрооткольные явления в толще необработанных образцов и микрооткольные явления на границе раздела упрочненного слоя с подложкой в обработанных пучком образцах.
\end{abstract}

DOI: $10.21883 /$ JTF.2018.05.45903.2205

\section{Введение}

С конца XX в. и по настоящее время при изготовлении конструкций из металлов и сплавов, работающих в условиях экстремальных внешних воздействий, в том числе в агрессивных средах, широкое распространение получили методы обработки поверхности изделий концентрированными потоками энергии. К таким методам относятся методы газотермического напыления, лазерная и электронно-пучковая обработка.

Концентрированные потоки энергии (КПЭ), которые создаются импульсными электронными пучками, воздействуя на поверхность деталей, способствуют быстрым структурно-фазовым превращениям в приповерхностных слоях металла. При определенном подборе параметров пучков без нагрева глубинных слоев металла, не вызывая напряжений, деформаций и изменений геометрических размеров, например, можно добиться резкого увеличения износостойкости детали [1] путем упрочнения ее поверхностного слоя.

Суть метода модификации заключается в следующем. При воздействии мощных импульсных электронных пучков на материал его слой толщиной порядка длины пробега электронов в данном материале (от 10 до $100 \mu \mathrm{m})$ очень быстро нагревается до температуры фазовых переходов. По окончании импульсного воздействия за счет теплопроводности в глубину материала нагретый слой быстро охлаждается.

В результате электронно-пучкового воздействия изменяются свойства поверхностного слоя:
1. Изменяется микроструктура - размер зерна уменьшается от сотен микрон до долей микрона, возможен переход в аморфное состояние и формирование наноструктур. Достаточно резко повышается микротвердость слоя по отношению к подложке.

2. Изменяется фазовый состав, при этом возможно появление метастабильных фаз и соединений, которые при обычных методах термообработки образоваться не могут.

3. Гомогенизируется фазовый состав, например, измельчаются и однородно распределяются карбиды в сталях.

Таким образом, в результате модификации поверхности импульсным электронным пучком (ИЭП) получается своеобразный слоеный материал, свойства которого в общем случае могут отличаться от исходного. В связи с этим перед разработчиками изделий с обработанной ИЭП поверхностью, которые подвергаются ударным нагрузкам, встает проблема оценки влияния модификации поверхности материала на динамические свойства (в частности, на откольную прочность и откольную стойкость) материала в целом. Кроме этого, у металловедов и специалистов в области механики деформируемого твердого тела возникают вопросы фундаментального характера, связанные с влиянием упрочненного поверхностного слоя на процессы динамического деформирования и разрушения как в самом слое, так и в подложке. Именно поэтому настоящая работа посвящена всем вышеперечисленным аспектам поведения и свойств материалов (откольной прочности и стойкости) с модифицированной ИЭП поверхностью. 
Таблица 1. Свойства титанового сплава $3 \mathrm{M}$

\begin{tabular}{c|c|c|c|c|c|c|c|c}
\hline $\begin{array}{c}\text { Плотность } \\
\rho_{0}, \mathrm{~kg} / \mathrm{m}^{3}\end{array}$ & $\begin{array}{c}\text { Коэффициент } \\
\text { Пуассона }\end{array}$ & $\begin{array}{c}\text { Модуль } \\
\text { Юнга, GPa }\end{array}$ & $\begin{array}{c}\text { Объемная скорость } \\
\text { звука } c_{0}, \mathrm{~m} / \mathrm{s}\end{array}$ & $\begin{array}{c}\sigma_{0,2}, \\
\mathrm{GPa}\end{array}$ & $\begin{array}{c}\sigma_{b}, \\
\mathrm{GPa}\end{array}$ & $\begin{array}{c}\delta_{5}, \\
\%\end{array}$ & $\begin{array}{c}\psi, \\
\%\end{array}$ & $\begin{array}{c}\mathrm{HV}, \\
\mathrm{GPa}\end{array}$ \\
\hline 4540 & 0.3 & 112 & 4530 & $660 \pm 10$ & $715 \pm 10$ & $22 \pm 1$ & $36 \pm 1$ & $4.35 \pm 0.26$
\end{tabular}

\section{Экспериментальные методики, материалы, режимы обработки}

Исследование откольной прочности проводилось на установке ПГ-57 в плосковолновой постановке с использованием интерферометра VISAR для регистрации скорости свободной поверхности. Основой установки ПГ-57 является газовая пушка калибром $57 \mathrm{~mm}$ с двухдиафрагменным затвором, работающая на сжатом воздухе или гелии давлением до $15 \mathrm{MPa}$. Применение газовой пушки позволяет получать стабильные и легко контролируемые скорости соударения $V_{0}$ в диапазоне от 50 до $500 \mathrm{~m} / \mathrm{c}$.

B качестве источника излучения в интерферометре VISAR использовался одномодовый и одночастотный неодимовый лазер Verdy-2 фирмы Coherent (США) со встроенным удвоителем частоты. Длина волны излучения $0.53 \mu \mathrm{m}$.

Обработка полученных интерферограмм производилась только до появления первого минимума зависимости скорости откольной поверхности от времени (так называемого откольного импульса) [2]. По полученным зависимостям скорости свободной поверхности определялись максимум скорости свободной поверхности $W_{1}$, минимальная скорость свободной поверхности $W_{2}$ перед началом откольного импульса, время спадания скорости свободной поверхности от $W_{1}$ до $W_{2}$. При проведении испытаний у некоторых образцов произошло выпучивание тыльной поверхности. Все остальные образцы были разрезаны для получения информации о наличии видимого откола (определялся по наличию магистральной трещины внутри образца) и его толщине.

Максимальные растягивающие напряжения $\sigma_{p}$ и скорость деформации $\dot{\varepsilon}$ определялись по формулам

$$
\begin{gathered}
\sigma_{p}=0.5 \rho_{0} c_{0}\left(W_{1}-W_{2}\right), \\
\dot{\varepsilon}=\frac{1}{c_{0}} \cdot \frac{\partial W_{1}}{\partial t},
\end{gathered}
$$

где $\rho_{0}-$ плотность материала образца; $c_{0}$ - объемная скорость звука.

При наличии откола (магистральной трещины) $\sigma_{p}$ соответствует откольной прочности. При наличии единичных микротрещин $\sigma_{p}$ характеризует откольную стойкость материала. Отметим, что откол наблюдался только в образцах с необработанной поверхностью. В целом $\sigma_{p}$ характеризует динамическую прочность материала.

Плосковолновые эксперименты по определению откольной прочности проводились с образцами из титанового сплава $3 \mathrm{M}$. Титановый сплав $3 \mathrm{M}$ относится к группе термически неупрочняемых $\alpha$-сплавов мартенситного класса средней прочности, допускающих упрочнение при закалке. Основные свойства исследуемого материала, необходимые для обработки динамических экспериментов, а также стандартные механические свойства, определенные на образцах из прутков, из которых впоследствии изготавливались все необходимые образцы для исследований, приведены в табл. 1. В последнем столбце табл. 1 приведены значения микротвердости, измеренные по высоте сечения плоского образца, толщиной $6 \mathrm{~mm}$.

Испытывались образцы двух видов: образцы диаметром $30 \mathrm{~mm}$ и толщиной $4 \mathrm{~mm}$, у которых поверхность, по которой наносился удар, была обработана электронным пучком и для сравнения толщиной $6 \mathrm{~mm}$ и диаметром $92 \mathrm{~mm}$ в исходном состоянии. Режим обработки образцов ИЭП состоял из восьми импульсов электронного пучка с плотностью энергии $18 \mathrm{~J} / \mathrm{cm}^{2}$ со средней длительностью каждого импульса $5 \mu \mathrm{s}$. Толщина модифицированного слоя $25 \pm 15 \mu \mathrm{m}$. Микротвердость слоя $\mathrm{HV}=4.89 \pm 0.66 \mathrm{GPa}$, микротвердость подложки - $\mathrm{HV}=4.29 \pm 0.30 \mathrm{GPa}$.

Для размещения в узле крепления образцов установки подобные образцы помещались в обойму с внешним диаметром $92 \mathrm{~mm}$, сделанную из того же материала, что и образцы (не обработанные электронным пучком). Тыльная поверхность всех образцов шлифовалась (но не полировалась) до получения матовой поверхности. Это позволило иметь достаточно контрастную интерференционную картину при небольших мощностях лазерного излучения $(\sim 20-30 \mathrm{~mW})$.

В качестве ударников использовались пластины из того же материала, что и исследуемые образцы. Толщина пластин-ударников составляла $3 \mathrm{~mm}$ для образцов толщиной $6 \mathrm{~mm}$ и $2 \mathrm{~mm}$ для образцов толщиной $4 \mathrm{~mm}$. Пластины-ударники толщиной $2 \mathrm{~mm}$ имели также как и образцы, диаметр $30 \mathrm{~mm}$ и со стороны, которой наносился удар, также обрабатывались электронным пучком.

После динамических испытаний по определению откольной прочности испытанные образцы, у которых произошло отделение откольной тарелочки, разрезались вдоль диаметра и из них, а также уже из разрезанных образцов с откольной тарелочкой изготавливались металлографические шлифы. Травление образцов осуществлялось последовательным погружением в растворы плавиковой и азотной кислот. Для рассмотрения и фиксации структур, выявленных на шлифах проб мишеней, применялся световой микроскоп „Аксио Обсервер“. 
Таблица 2. Результаты динамических испытаний

\begin{tabular}{c|c|c|c|c|c|c}
\hline № & Обработка & $V_{0}, \mathrm{~m} / \mathrm{s}$ & $W_{1}, \mathrm{~m} / \mathrm{s}$ & $W_{2}, \mathrm{~m} / \mathrm{s}$ & $\dot{\varepsilon}, \mathrm{s}^{-1}$ & $\sigma_{p}, \mathrm{GPa}$ \\
\hline 1 & Без обработки & 495 & 493 & 198 & 4.65 & 3.03 \\
2 & & 500 & $670^{*}$ & 299 & 5.2 & 3.82 \\
3 & С обработкой & 411 & 415 & 163 & 4.9 & 2.6 \\
4 & фронтальной & 438 & 440 & 266 & 4.8 & 1.8 \\
5 & поверхности & 484 & 480 & 142 & 5.4 & 3.4 \\
& ИЭП & & & & &
\end{tabular}

Примечание: *Материал ударника - сталь 12 Х18Н10T.
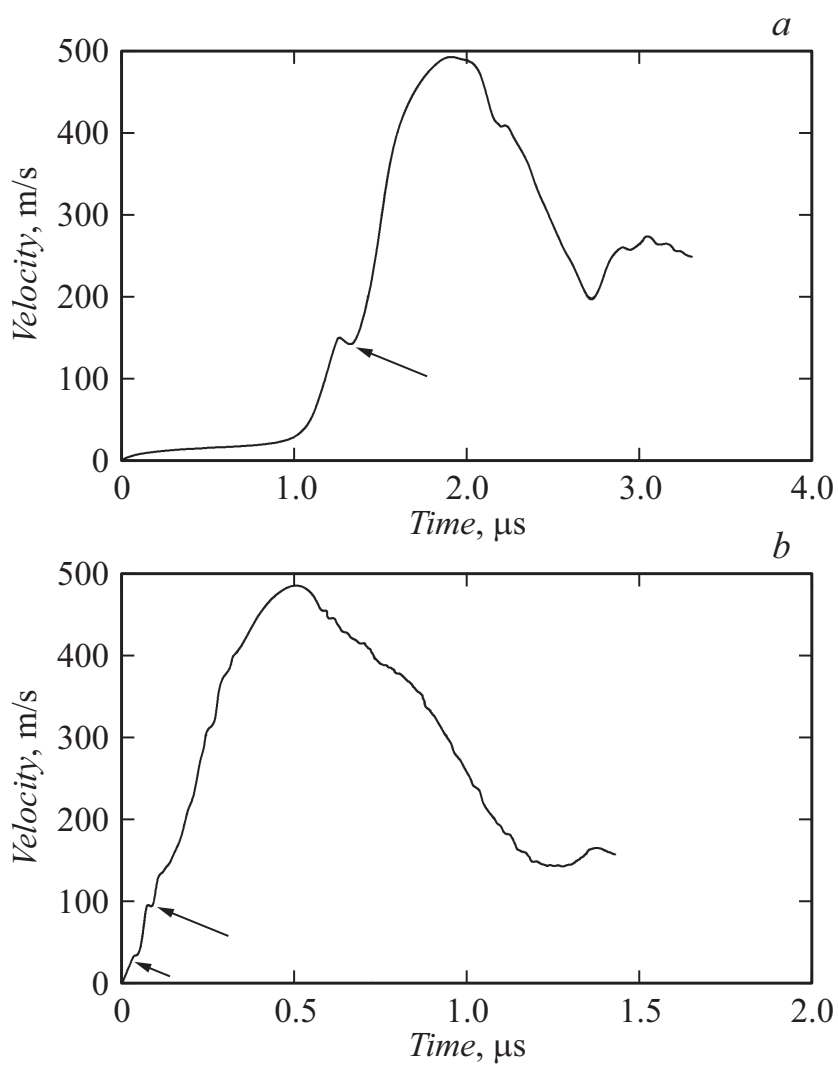

Рис. 1. Экспериментальные зависимости изменения скорости свободной поверхности образцов от времени: $a$ - скорость удара $495 \mathrm{~m} / \mathrm{s}, b-$ скорость удара $484 \mathrm{~m} / \mathrm{s}$.

Для определения значений микротвердости использовался микротвердомер „Аффри“, замеры микротвердости осуществлялись при нагрузке на индентор усилия $50 \mathrm{~g}$.

\section{Результаты плосковолновых экспериментов и их обсуждение}

Результаты экспериментов по определению откольной прочности сведены в табл. 2. На рис. 1 представлены примеры экспериментальных зависимостей изменения скорости свободной поверхности образцов от времени.

При анализе полученных результатов обращают на себя внимание следующие факты:
1. Несмотря на достаточно узкий диапазон изменений начальной скорости удара и скорости деформации наблюдается тенденция увеличения динамической прочности с увеличение двух указанных параметров процесса.

2. Значения максимальных растягивающих напряжений образцов с обработанной поверхностью на 10-20\% ниже, чем у образцов с необработанной поверхностью, для которых $\sigma_{0}$ является и откольной прочностью. Однако даже этот результат нельзя считать абсолютно достоверным, поскольку при расчете $\sigma_{p}$ для обработанных образцов пользовались теми же значениями $\rho_{0}$ и $c_{0}$, а они могут быть: плотность незначительно выше, а $c_{0}$ более выше, чем в случае необработанных образцов [3].

3. Обращает на себя внимание более чем на $30 \%$ снижение значения $\sigma_{p}$ в эксперименте 4 , объяснение этого экспериментального факта будет дано в следующем разд. 3 настоящей работы.

4. На многих профилях скорости свободной поверхности образцов как с обработанной поверхностью, так и с необработанной (в том числе и в экспериментах, которые не приведены в таблице) в интервале скоростей $150-200 \mathrm{~m} / \mathrm{s}$ обнаружены некие зубцы (показаны большими стрелками на рис. 2). Каждый из зубцов внешне похож на зуб текучести в малоуглеродистых сталях и в ОЦК-металлах [4]. Возможно, эти зубцы связаны с осцилляциями фронта пластической волны, которые
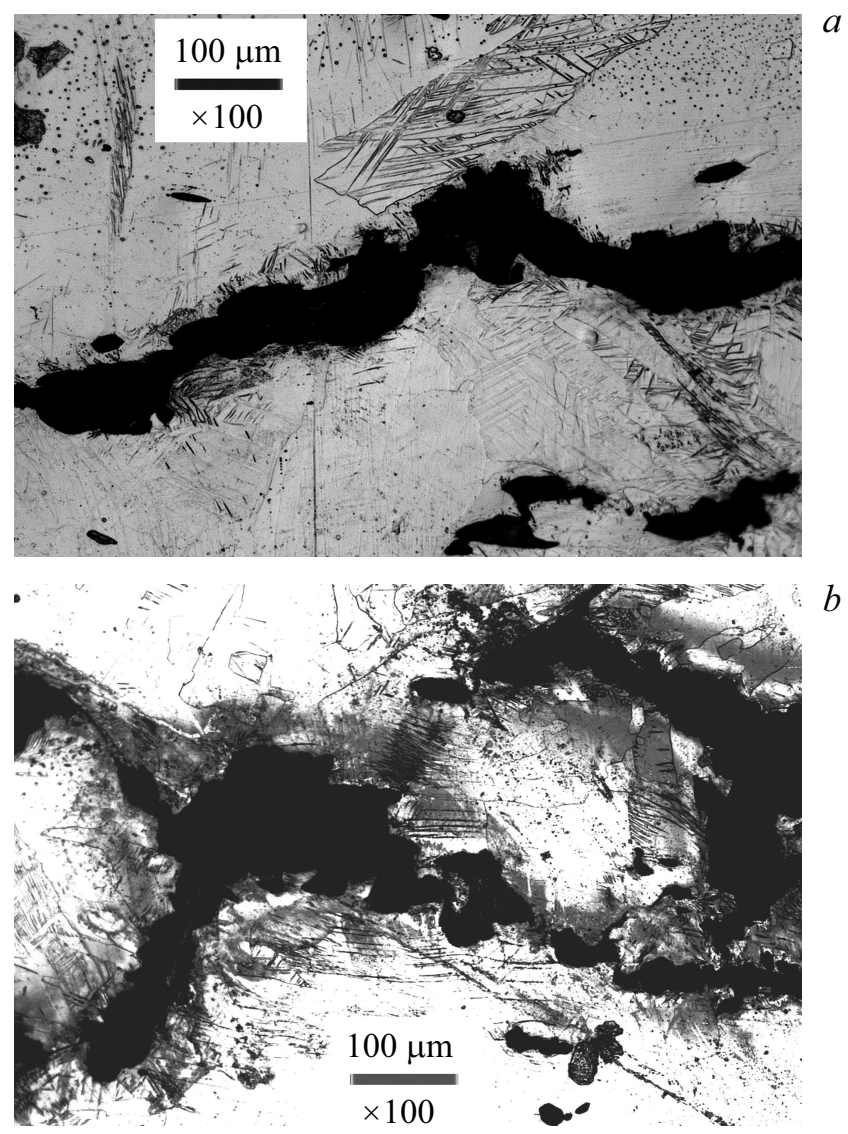

Рис. 2. Несплошности в образцах после удара со скоростью $495(a)$ и $500 \mathrm{~m} / \mathrm{s}(b)$. 
наблюдались в работах $[5,6]$. В указанных работах такие осцилляции объяснялись с точки зрения особенностей пластической деформации, осуществляющейся за счет гетерогенного размножения дислокаций или движения диполей частичных дисклинаций. Вероятно, возможны и другие объяснения этого явления.

5. На профилях скорости свободной поверхности образцов с обработанной поверхностью видны небольшие уступы (показан пример на рис. $1, b$ малой стрелкой), которые могут быть связаны с тем, что в случае обработанной поверхности могут изменяться механизмы упругой и пластической деформации. Такие изменения могут быть связаны, например, с появлением неких высокоскоростных кооперативных атомных перемещений или дополнительных одиночных дефектов и др.

\section{Результаты исследования структур и их обсуждение}

Прежде всего на протравленных образцах были произведены замеры микротвердости по всей высоте исследуемого образца. Такую микротвердость, являющуюся следствием ударного нагружения, в дальнейшем будем называть наведенной микротвердостью. Для каждого образца было произведено не менее десяти замеров. Полученные результаты сведены в табл. 3.

Анализ результатов, приведенных в табл. 3, показал:

1. Ударное нагружение образцов в целом привело к их упрочнению. Исключение составляет образец 4, где микротвердость осталась практически на исходном уровне.

2. Откольная прочность образцов и максимальные растягивающие напряжения коррелируют со средней наведенной микротвердостью материала образцов: чем выше значения последней, тем выше значения $\sigma_{p}$ (практически линейная зависимость). Таким образом, находит объяснение факт уменьшения максимальных растягивающих напряжений $\sigma_{p}$ для образца 4.

Металлографические исследования структур образцов показали, что откольные явления имели место только в образцах с необработанной поверхностью, в которых приблизительно на расстоянии $2 \mathrm{~mm}$ от тыльной (свободной) поверхности наблюдалось зарождение откольной щели (магистральная трещина отсутствовала) в виде

Таблица 3. Откольная прочность и максимальные растягивающие напряжения и микротвердость исследованных образцов

\begin{tabular}{c|c|c|c|c}
\hline № & Обработка & $V_{0}, \mathrm{~m} / \mathrm{s}$ & $\sigma_{p}, \mathrm{GPa}$ & $\mathrm{HV}, \mathrm{GPa}$ \\
\hline 1 & Без обработки & 495 & 3.03 & $5.00 \pm 0.30$ \\
2 & & 500 & 3.82 & $5.80 \pm 0.35$ \\
3 & С обработкой & 411 & 2.6 & $4.80 \pm 0.25$ \\
4 & фронтальной & 438 & 1.8 & $4.10 \pm 0.20$ \\
5 & поверхности ИЭП & 484 & 3.4 & $5.70 \pm 0.29$
\end{tabular}
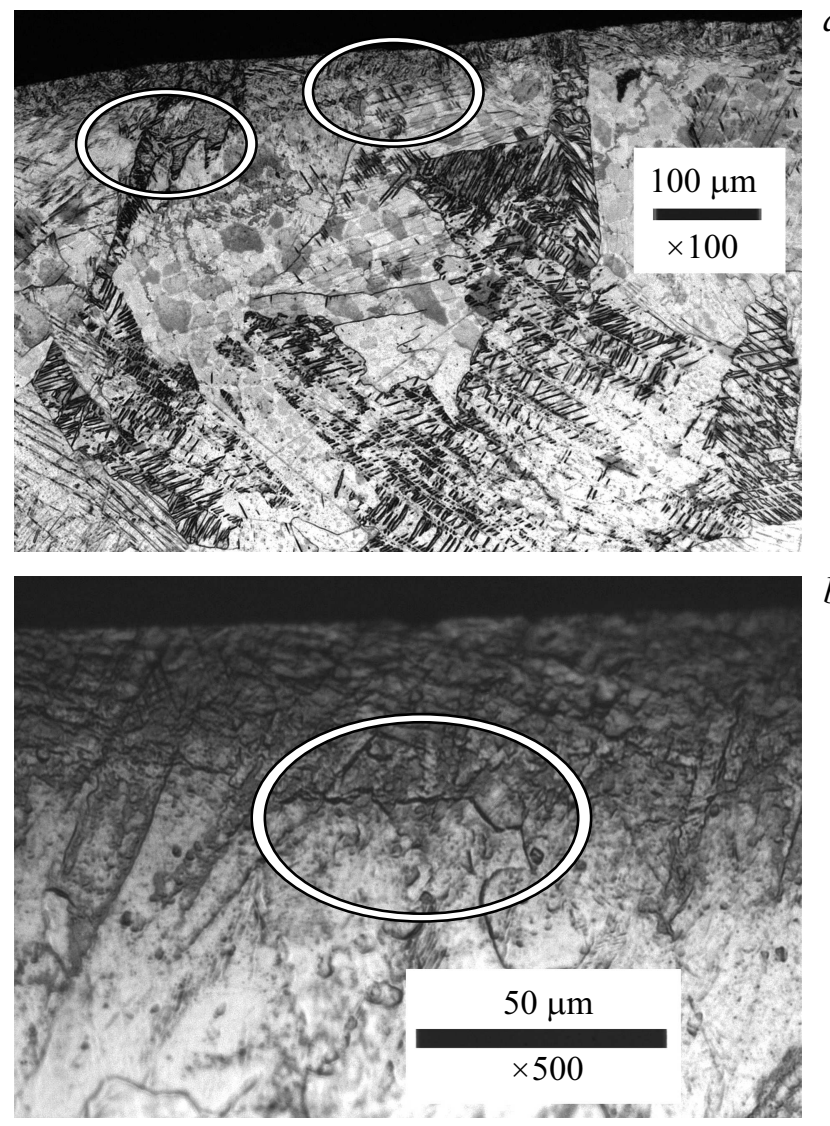

Рис. 3. Квазипериодический рельеф из микротрещин в образцах после удара со скоростью 438 (a) и $484 \mathrm{~m} / \mathrm{s}(b)$.

либо отдельных трещин мезомакромасштабного уровня, либо скопления трещин (рис. 2).

Для образцов с обработанной поверхностью таких нарушений сплошности образцов не наблюдалось. Однако у границы раздела упрочненного слоя с подложкой наблюдался квазипериодический с шагом $\sim 2 \mu \mathrm{m}$ микрорельеф, сформированный из микротрещин указанного размера (рис. 3).

Такой рельеф, вероятно, является микрооткольной щелью между упрочненным слоем и подложкой, что связано с различиями в их значениях акустического импеданса. В этом случае волна сжатия с амплитудой на фронте $p_{0}=\left(\frac{R_{0} R_{1}}{R_{0}+R_{1}}\right) V_{0}$ и массовой скоростью $U_{0}=\left(\frac{R_{0}}{R_{0}+R_{1}}\right) V_{0}$ (здесь $R_{0,1}-$ соответствующие импедансы ударника и упрочненного слоя), сформировавшаяся в момент удара по фронтальной обработанной поверхности, пройдя упрочненный слой, войдет в подложку, и от границы раздела в обе стороны будет распространяться с отличным от $p_{0}$ пиковым давлением и массовой скоростью, отличной от $V_{0}$. В конечном итоге интерференция волн разрежения от фронтальной поверхности вызовет некоторое подобие микрооткола. В целом же, наличие упрочненного слоя приводит к дис- 
сипации механической энергии первоначальной ударной волны, чем и объясняется отсутствие макрооткольных процессов в толще образца.

\section{Заключение и выводы}

Анализ эффектов, связанных с наличием упрочненного импульсным электронным пучком микросекундной длительности поверхностным слоем в титановом сплаве 3М, приводит к следующим выводам:

1. Динамическая прочность образцов из титанового сплава 3М с обработанным импульсным электронным пучком поверхностным слоем выше, чем у образцов без обработанной поверхности.

2. Динамическая прочность исследованного материала (независимо от обработки поверхностного слоя) растет с увеличением скорости деформации. Динамическая прочность также коррелирует со средней наведенной микротвердостью образцов: чем она выше, тем выше динамическая прочность материала.

3. Небольшие уступы (соответствуют малым длительностям процесса (до $200 \mathrm{~ns})$ ) на профилях скорости свободной поверхности образцов с обработанной поверхностью с некоторой долей вероятности связаны с тем, что в случае обработанной поверхности изменяются механизмы упругой и пластической деформации. В частности, могут проявиться высокоскоростные кооперативные атомные перемещения или некие эффекты мезоскопического масштабного уровня.

4. Аналоги зуба текучести в малоуглеродистых сталях и в ОЦК-металлах, проявляющиеся на полученных профилях скорости свободной поверхности в виде зубцов, могут быть связаны с осцилляциями фронта пластической волны. Однако не отрицаются и другие (не выявленные) причины появления указанных зубцов.

\section{Список литературы}

[1] Рыкалин Н.Н., Зуев И.В., Углов А.А. Основы электроннолучевой обработки материалов. М.: Машиностроение, 1978. 239 c.

[2] Разрушение разномасштабных объектов при взрыве / Под общей ред. А.Г. Иванова. Саров: РФЯЦ-ВНИИЭФ, 2001. $482 \mathrm{c}$.

[3] Судьенков Ю.В. Особенности ударноволнового процесса в твердых телах вблизи поверхности высокоскоростного нагружения // Проблемы динамических процессов в гетерогенных средах. Калинин: Изд-во Калининского гос. ун-та, 1987. C. $120-126$.

[4] Криштал M.M. Неустойчивость и мезоскопическая неоднородность пластической деформации (аналитический обзор). Ч. І. Феноменология зуба текучести и прерывистой текучести // Физическая мезомеханика. 2004. Т. 7. № 5. C. 5-29.
[5] Байзаков О.Д., Макаревич И.П., Морозов В.А., Судьенков Ю.В. Осцилляции пластического течения в металлах за фронтом упругого предвестника // Проблемы динамических процессов в гетерогенных средах. Калинин: Изд-во Калининского гос. ун-та, 1987. С. 127-132.

[6] Мещеряков Ю.И., Савенков Г.Г. // ПМТФ. 2001. Т. 42. № 6. C. $17-123$. 